\title{
Editorial
}

\section{Sobre o Parágrafo Mais Importante do Artigo Científico}

$\mathrm{Na}$ época da seca em Brasília, temos o prazer de entregar a nossos leitores o terceiro número do Volume 15 de Psicologia: Teoria e Pesquisa, correspondente ao ano de 1999. Com ele, estamos muito perto de ter nossa periodicidade regularizada no sentido estrito do termo. E com ele, no prazo de um ano e dois meses entregamos seis números e publicamos 62 artigos.

Todavia, o problema da regularização da periodicidade não é desligado de outros problemas da produção editorial. O da regularização é talvez até simples de ser resolvido, quando comparado ao problema da tramitação dos manuscritos. No primeiro caso, há até o recurso desesperado ao dirty work da compactação mas, no que toca a tramitação, esta traz os problemas mais complicados para o gerenciamento editorial. Na minha experiência é onde o processo editorial emperra. Não tenho a intenção de discuti-lo, como tem feito em comunicações pessoais nossa ex-editora, Célia Zannon, mas apenas contribuir para que esse problema seja minorado. Penso que a natureza democrática da revisão por pares de especialistas contribui para que a tramitação seja morosa. O processo democrático é moroso. Exige discussão, crítica e contra-crítica, avaliação, equilíbrio na decisão, e estas não são tomadas assim, no estalar dos dedos. Penso também que a revista pode contribuir para melhorar o processo de tramitação através do cumprimento de sua função didática, de socialização do conhecimento. Nesse sentido, apresentarei o tratamento dado pelo Manual da APA (1994) a uma parte do manuscrito que muitos autores descuidam: o Resumo ou Abstract.

O Manual de Publicação da APA (1994) considera o resumo (abstract) um parágrafo do artigo $e$ o mais importante, porque ele constitui o primeiro contato do leitor com um artigo; é com base no resumo que ele toma a decisão de ler ou não o trabalho inteiro. Nossa experiência tem mostrado que a maioria dos autores que submetem manuscritos a $P s i$ cologia: Teoria e Pesquisa dedicam pouca atenção ao resumo; e isto não é privilégio de novatos pois inclui também muitos autores experientes.

O que talvez não seja claro para esses autores é que o resumo será usado de modo similar ao uso que é feito do título. De acordo com o Manual da APA (1994), o resumo "é usado pelos serviços de sumarização e informação para indexar e recuperar artigos a partir de um computador." (p. 8), por isso ele recomenda que os resumos não devem exceder o limite de palavras previsto para a categoria do artigo, uma vez que os sumarizadores acabarão por fazer cortes no resumo para obter seu ajustamento à base de dados.

Uma descrição das qualidades do bom resumo é feita no Manual. Elas são divididas em cinco características: exatidão, auto-contenção, concisão e especificidade, não valoração, coerência e de boa leitura (readable).
Quanto à "Exatidão", a regra principal é que o resumo deve informar corretamente sobre o propósito e o conteúdo do manuscrito e que ele não pode conter informações que não apareçam no corpo do artigo.

No que diz respeito à "Auto-contenção" a regra é definir e explicitar, ou seja, que o leitor não precise recorrer ao corpo do artigo para saber o significado de abreviações, acrossemias e termos singulares. Assim, recomenda o Manual, que todas as abreviações (salvo as unidades de medida) e acrossemias ou seja, palavras formadas a partir de, letras iniciais de outras palavras, por ex. ONU (Organização das Nações Unidas) e termos singulares devem ser definidos, assim como devem ser explicitados nomes de testes e de drogas. Para evitar o uso da repetição exata de passagens de outros autores (o que não é incomum encontrar nos manuscritos de nossos autores), o Manual recomenda o uso da paráfrase. Ou seja, é preferível expressar o significado da passagem do autor referido com palavras diferentes das suas que repeti-las exatamente.

O tópico "Concisão e Especificidade" trata do melhor aproveitamento do espaço. Repetir o título no resumo é desperdício de espaço. Assim também o é começar uma sentença com um número. Na medida em que dígitos podem ser usados para todos os números, o desperdício é grande se pensarmos uma frase do seguinte tipo "Setecentos e trinta e nove alunos de escolas públicas etc", ou seja, neste caso são usadas cinco palavras quando poderia ser usado apenas um número no meio do período. Trata-se de aproveitar o espaço para oferecer a informação máxima. Nesse sentido, o Manual da APA (1994) recomenda que o resumo deve oferecer a informação mais importante, especialmente a sentença inicial, e nele devem ser incluídos "apenas os 4 ou 5 conceitos, resultados ou implicações mais importantes" (pag. 9). Qual é a informação mais importante? Ela depende do que foi estabelecido pelo autor: para alguns o propósito ou a tese em questão, para outros os resultados e conclusões.

A "Não-Valoração" consiste de apenas uma regra: o autor relata sem fazer avaliações, comentários ou acréscimos ao que está no corpo do manuscrito. Ele deve relatar o conteúdo e o objetivo do artigo, sem introduzir novas avaliações, e/ou comentários que não constem do corpo do artigo-

No que se refere à característica "Coerência e de Boa Leitura", dentre as recomendações do Manual, pareceu-nos central a regra que pede ao autor que evite sentenças que não contenham informação real. As demais recomendações tratam do uso dos tempos verbais (o presente para descrever resultados ou conclusões e o passado para descrição de variáveis específicas manipuladas ou testes aplicados), do uso da voz ativa de preferência à passiva e do uso da terceira pessoa sempre que possível. 
Uma vez descritas as qualidades características de um bom resumo e as recomendações feitas para obtenção desse bom resultado, o Manual apresenta sinteticamente os pontos que devem constar de um resumo, considerando as diferenças quanto à categoria dos artigos: relato de estudo empírico, revisão ou teórico. Considerando a utilidade que possa ter para muitos autores o roteiro previsto pelo Manual (1994, p. 10), transcrevo em seguida a tradução que fiz do mesmo:

\section{Resumo do relato de um estudo empírico:}

- o problema da pesquisa, se possível em uma sentença;

- os sujeitos, especificando características pertinentes, tais como, número, tipo, idade, sexo, e gênero e espécie;

- o método experimental, incluindo o equipamento, procedimento de coleta de dados, nomes completos dos testes, nomes genéricos completos e a dosagem e rotas de administração de quaisquer drogas (particularmente se as drogas são novas ou importantes para o estudo);

- os resultados, incluindo níveis de significância estatística;

- as conclusões e as implicações ou aplicações.

\section{Artigos de Revisão ou Teóricos:}

- o tópico em uma sentença;

- o propósito, a tese, ou constructo organizador e a abrangência (compreensiva ou seletiva) do artigo;

- as fontes usadas (p. ex., observação pessoal, literatura publicada etc);

- conclusões.
Em minha experiência editorial encontrei algumas falhas constantes na apresentação de resumos de relatos de pesquisa empírica, quando vistas à luz do roteiro acima. A falha mais comum é a descrição precária das amostras de sujeitos. Alguns limitam-se a dizer: "Foram sujeitos do experimento crianças de 4 e 5 anos", e isto é tudo que é informado da amostra. Noutros casos toda a informação dada ao leitor sobre os sujeitos resume-se na descrição da amostra como tendo sido composta de universitários da cidade $\mathrm{X}$.

Em segundo lugar, a falha mais comum é a não apresentação, na parte dos resultados, de níveis de significância estatística que aparecem no corpo do artigo. E, uma terceira falha também comum é a ausência de qualquer menção, na parte que trata das conclusões, das implicações ou aplicações que estas possam ter.

Para concluir, basta dizer que a regra válida para o leitor, ou seja, ele lê ou não lê o artigo dependendo do que encontra no resumo, vale também para os revisores. Um resumo precário pode levá-los a devolver o manuscrito recusandose a revisá-lo, quando não simplesmente ignoram nossa solicitação.

\section{Referência}

American Psychological Association (1994). Publication Manual (4. ed.). Washington, DC: Autor.

Norberto Abreu e Silva Neto 